\title{
Environmental performance evaluation in developing the plan of coordination of an isolated intersection
}

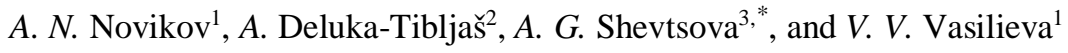 \\ ${ }^{1}$ Orel State University named after I.S. Turgenev, Orel, Russia \\ ${ }^{2}$ Faculty of Civil Engineering University of Rijeka, Rijeka, Croatia \\ ${ }^{3}$ Belgorod State Technological University named after V.G. Shukhov, Belgorod, Russia
}

\begin{abstract}
This article analyzes existing research in the field of assessing the effectiveness of changing the coordination plan of a traffic light object. As a result of the studies, the basic parameters necessary for the assessment, such as vehicle delays, fuel consumption and the amount of harmful emissions, are determined. An approach is proposed for determining the amount of harmful emissions and the degree of their reduction when establishing the necessary coordination plan. An experiment was carried out and the results obtained were evaluated.
\end{abstract}

\section{Introduction}

The quality of various options for traffic management schemes, as well as checking the various durations of regulation modes at intersections, is estimated by the average delay of vehicles, this indicator is directly proportional to the degree of saturation of directions $x$ [1]. This value is dimensionless, its physical meaning lies in the ratio of the average number of arriving vehicles to the intersection during the cycle to the maximum number of vehicles leaving for the enable signal and it directly depends on the value of the saturation flux.

Today there are a large number of simulation products [2-4] that allow you to evaluate the quality of various traffic management schemes, including determine the degree of saturation. This value is defined as the ratio of the load to the throughput, where the load (hourly intensity) is the input quantitative indicator of the traffic flow determined by the user, and the throughput is the number of vehicles that can be detected under normal traffic conditions in the network. At the design stage, based on the value of this quantity, it is possible to evaluate the developed scheme of traffic organization using traffic light control. Despite the multifunctionality of this value, it does not allow us to assess the environmental effectiveness of changing the coordination plan. The main parameters with which it is possible to carry out an environmental assessment are delays in traffic flow, fuel consumption and the amount of harmful emissions. To develop an approach to assessing environmental performance in the framework of this study, an analysis of the previously listed values was performed.

\footnotetext{
*Corresponding author: shevcova-anastasiya@mail.ru
} 


\section{Analysis of key values for environmental performance assessment}

\subsection{Study of vehicle delay}

One of the most important indicators of the effectiveness of traffic is the amount of delay at the intersection, it characterizes not only the indirect costs of drivers, expressed in loss of time, experienced discomfort and fatigue, but also direct costs due to fuel consumption during engine idle at stops. Long delays at the regulated intersection indicate the inefficiency of the mode used.

Basically, in simulation products, the control delay is determined by the formula:

$$
d=d_{1} P F+d_{2}+d_{3}
$$

where $d_{1}$ - uniform delay, s/car; $P F$ - coefficient of adjustment for the possibility of unhindered movement; $d_{2}$ - random delay, s/car; $d_{3}$ - residual delay, s/car.

Since $d_{1}$ is calculated by integrating the profile of the queue modules, the $P F$ value is accepted 1 . Thus, the delay in the program is calculated as the sum of three components, similar to the classical calculation according to the formula of F. Webster [5]:

$$
t_{p}=\frac{T(1-\lambda)^{2}}{2(1-\lambda \chi)}+\frac{\chi^{2}}{2 N(1-\chi)}-0.65\left(\frac{T}{N^{2}}\right)^{1 / 3} \chi^{(2+5 \lambda)}
$$

where $t_{p}$ - is the average delay per cycle, $\mathrm{s} ; T$ - the length of the regulation cycle, $\mathrm{s} ; x$ is the degree of saturation; $\lambda$ - the ratio of the duration of the enable signal to the cycle; $N$ is the traffic intensity of the vehicles in the direction in question, units/s.

The first part of formula 2 allows you to determine the delay in the regular arrival of cars at the intersection. The second takes into account the random nature of arrival and allows you to determine the average delay in this direction of the intersection. The third allows you to take into account the error in calculating the delay for the first two components.

\subsection{Study of fuel consumption}

In simulation products, fuel consumption is estimated based on a linear combination of full mileage, delays and stops. The obtained value of fuel consumption includes fuel consumed while driving, at idle and during periods of acceleration and braking. The mathematical model for determining fuel consumption according to research by H. Lorix and C. Valis [6] is as follows:

$$
F=K_{i 1} \cdot T T+K_{i 2} \cdot D+K_{i 3} \cdot S
$$

where $F$ is the fuel consumption, $\mathrm{l} / \mathrm{h} ; T T$ - full mileage in the car - $\mathrm{km} / \mathrm{h} ; D$ - full delay, auth/h; $S$ is the total number of stops per hour; $K_{i j}$ are the coefficients of the model, which serve as functions of cruising speed $\left(V_{\mathrm{i}}\right)$ on each segment $i$ [7].

\subsection{Study of the amount of harmful emissions into the atmosphere}

The estimation of losses from air pollution by harmful substances entering the atmosphere with exhaust gases from cars during the year on a certain section of the highway according to studies reflected in $[8,9]$ is determined taking into account the specific emission of harmful substances, and estimated $\mathrm{t} / 1000 \mathrm{~km}$ of run or $\mathrm{g} / 1 \mathrm{~km}$ : 


$$
C=\frac{0.365 L N_{p} m}{k_{\text {un }}} \sum D_{s i} C_{s i} b_{i}
$$

where $L$ is the length of the highway, $\mathrm{km} ; N_{p}$ - traffic intensity of a certain type of car at rush hour, auto/h; $m$ - coefficient taking into account the increase in fuel consumption when driving with frequent stops; $k_{u n}$ is the coefficient of uneven movement $\left(k_{u n}=0.1\right)$; $D_{s}$ specific emission of the $i$-th harmful substance; $C_{s}$ - specific damage from the emission of the $i$-th harmful substance, $\mathrm{p} / 1$ ton of substance; $b_{i}$ - coefficient taking into account the influence of the technical condition of the vehicle on the emission of harmful substances (in the absence of data, $b_{i}=1$ can be taken).

According to the instructions for calculating harmful emissions [10] during the combustion of $1 \mathrm{~kg}$ of gasoline for cars of ecological class above Euro 1, the specific emission of the main pollutants is:

1. Carbon monoxide (CO) - $21.5 \mathrm{~g} / \mathrm{kg}$. $\mathrm{g} / \mathrm{kg}$.

2. Hydrocarbons in terms of $\mathrm{CH}_{1.85}$ (including VOC contained in fuel vapor) (VOC) - 2.4

3. Nitrogen oxides in terms of $\mathrm{NO}_{2}\left(\mathrm{NO}_{\mathrm{x}}\right)-5.8 \mathrm{~g} / \mathrm{kg}$.

4. Sulfur dioxide $\left(\mathrm{SO}_{2}\right)-0.54 \mathrm{~g} / \mathrm{kg}$.

5. Carbon dioxide $\left(\mathrm{CO}_{2}\right)-3120 \mathrm{~g} / \mathrm{kg}$.

Knowing the fuel consumption in the studied area and the nominal value during the combustion of $1 \mathrm{~kg}$. fuel, it is possible to determine the value of harmful substances for evaluating the coordination plan of the traffic light.

As a result of the analysis of the main parameters of the traffic flow, allowing to evaluate the environmental efficiency of the traffic light coordination plan, the authors developed an approach to the assessment procedure (fig. 1).
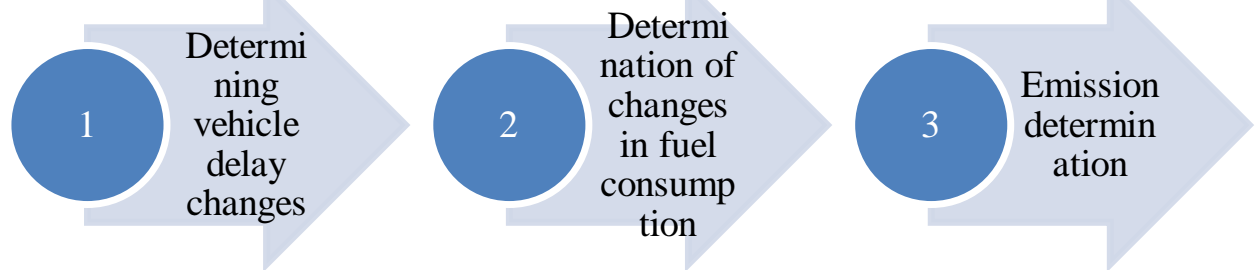

Fig. 1. An approach to assessing environmental performance when changing the coordination plan of a traffic light object

To test the proposed approach, a model experiment was performed in the framework of this study.

\section{Experiment}

The object of research is a classic crossroads with three phases of regulation. As a result of a previously performed study [11], the authors performed an optimization calculation of an isolated intersection; in the framework of this study, an environmental efficiency assessment was performed.

The results of calculating the average delay at the intersection in each direction are presented in fig. 2. 


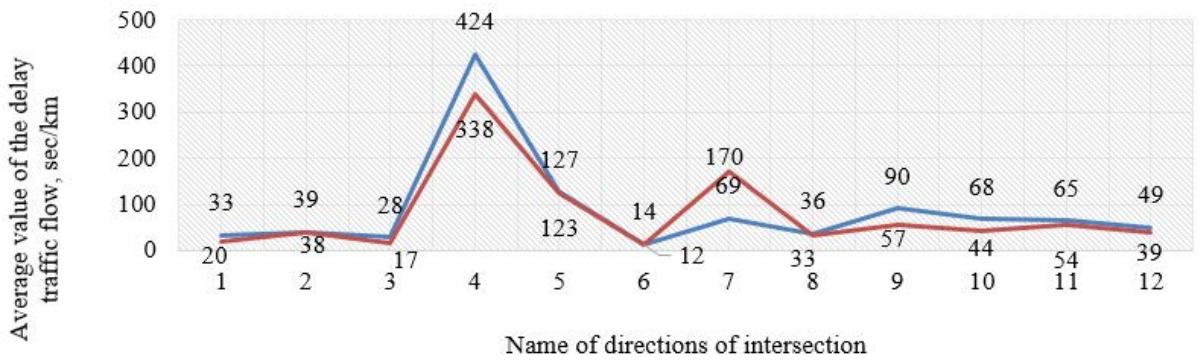

Fig. 2. Graph of changes in average delay in directions during simulation (where the blue line - with the existing coordination plan; red line with received coordination plan).

Considering all directions at the intersection, we can say that during the peak period under the existing mode of operation, the delay value averaged $87.4 \mathrm{~s}$, while in the calculated mode this value decreases and becomes equal to $79.1 \mathrm{~s}$. the average deviation is approximately $8 \%$.

As a result of the experiment, the fuel consumption values in each direction were obtained under the existing and calculated control modes (fig. 3), which made it possible to compare the results and the economic effect due to fuel economy at the intersection. Under the existing regime, fuel consumption at the entire intersection for an hour was 1005 liters, with the obtained value of the operation mode due to the reduction of delays, this value was 889 liters.

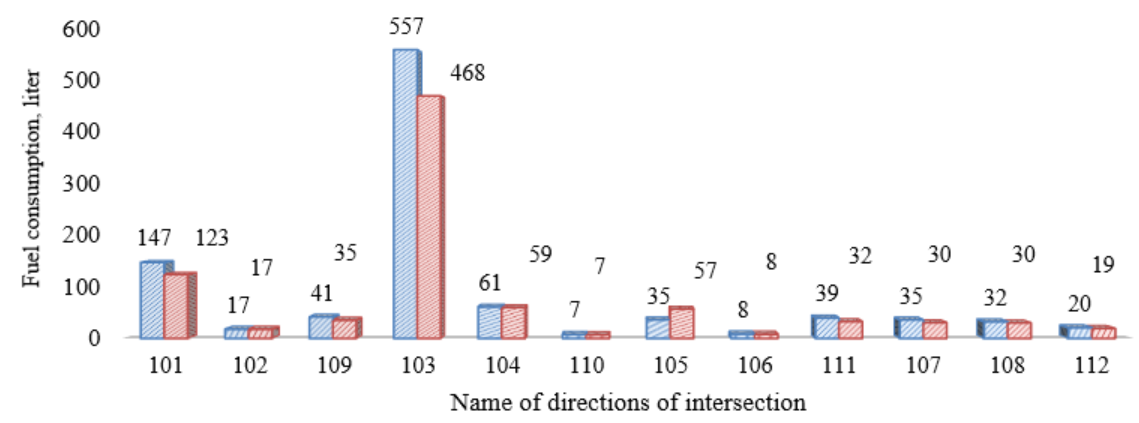

Fig. 3. Histogram of changes in fuel consumption in the studied areas (where the blue line - with the existing coordination plan; red line with received coordination plan).

According to the data obtained, harmful emissions are reduced in the study area, so when using the obtained regimes during the year, it is possible to reduce the emission of carbon monoxide by 0.837 tons, hydrocarbon by 0.093 tons, nitrogen oxides by 0.226 tons and sulfur dioxide by 0.021 tons (fig. 4).

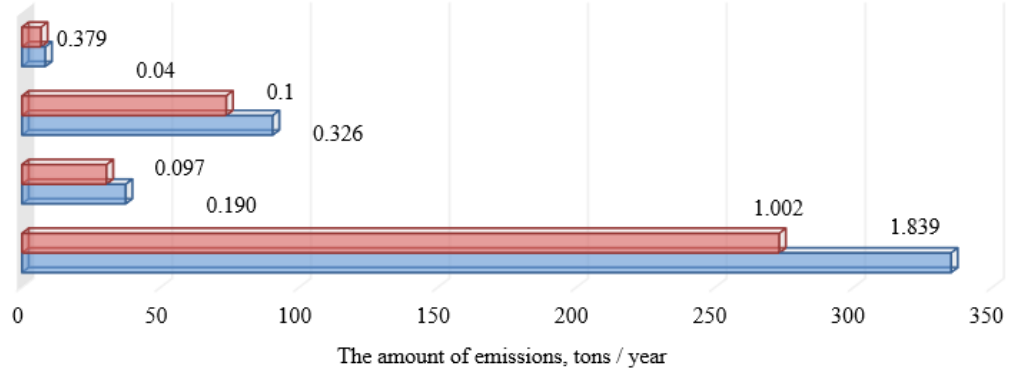

Fig. 4. Change in emissions of major harmful substances (where the blue line - with the existing coordination plan; red line with received coordination plan). 
When using the calculated operating modes of the traffic light object, the concentration of harmful emissions was reduced by an average of $11 \%$, which will generally improve the environmental situation.

\section{Conclusion}

As a result of the study, the authors systematized the approach to assessing environmental performance when changing the coordination plan of a traffic light object. Based on the experiment performed using the simulation product, the developed approach was tested and an environmental assessment was carried out, which, within the framework of the object of study, an isolated intersection, allowed us to determine the reduction of harmful emissions into the atmosphere by an average of $11 \%$, which generally improves the environmental situation.

\section{References}

1. Borovskoy A E and Shevtsova A G 2016 Study of the degree of intersection saturation taking into account the classification of cars Science and technology of transport Volume 1 pp. 88-93

2. Izyumsky A A, Nadiryan S L and Senin I S 2016 The use of simulation in the field of modeling traffic flows The science. Equipment. Technology (Polytechnic Bulletin) Volume 1 pp. 52-54

3. Babicheva T S 2015 The Use of Queuing Theory at Research and Optimization of Traffic on the Signal-controlled Road Intersections 3rd International Conference on Information Technology and Quantitative Management ITQM Volume 55 pp 469-478

4. Treiber M, Hennecke A and Helbing D 2000 Congested traffic states in empirical observations and microscopic simulations Physical Review E 62 (2) pp. 1805-1824

5. Kremenets Yu A, Pechersky M P and Afanasyev M B 2005 Technical means of traffic management (Moscow: Academic book) p. 279

6. Robertson D I 1968 TRANSYT: Traffic Network Study Tool Fourth International Symposium on the Theory of Traffic Flow (Karlsruhe, Germany)

7. Lorick H C, Wallace C.E. and Jamagin R.E. 1980 Analysis of Fuel Consumption and Platoon Dispersion Models (University of Florida Transportation Research Center, Report No. UF-TRC-U32-TR-02)

8. Korchagin V A and Rizaeva Yu N 2008 Evaluation of the effectiveness of engineering solutions (Lipetsk: LSTU) p. 160

9. Fedotov V N and Afanasiev A S 2018 Concept of air environment cleaning of natural and technogenic system of motor transport using mobile devices Transport Res. 36 pp. 17984

10. Settlement instruction (methodology) for the inventory of pollutant emissions from vehicles in the largest cities of 2008 (Moscow: Avtopolus-plus) p. 78

11. Novikov A, Novikov I and Shevtsova A 2019 Modeling of traffic-light signalization depending on the quality of traffic flow in the city Journal of Applied Engineering Science Volume 17(2) pp. 175-181 